\title{
Influence of feeding a low-phosphorus diet on leucocyte function in dairy cows
}

\author{
S. W. F. Eisenberg, ${ }^{* 1}$ L. Ravesloot, ${ }^{*}$ A. P. Koets, ${ }^{*} \dagger$ and W. Grünberg ${ }^{* 2}$ \\ *Department of Farm Animal Health, Faculty of Veterinary Medicine, NL-3584CL Utrecht, the Netherlands \\ †Division of Immunology, Department of Infectious Disease and Immunology, Faculty of Veterinary Medicine, NL-3584CL Utrecht, the Netherlands
}

\begin{abstract}
Phosphorus depletion and hypophosphatemia have been described to interfere with immune function in rats and humans. In dairy cows, hypophosphatemia has been associated with muscle weakness and recumbency as well as with intravascular hemolysis resulting from increased osmotic fragility of erythrocytes, but so far, the influence of $\mathrm{P}$ depletion and hypophosphatemia on immune function has not been studied. Therefore, the aim of this study was to investigate whether P depletion and ensuing hypophosphatemia are associated with impaired granulocyte and lymphocyte function. Eight mid-lactation dairy cows were fed a P-deficient ration $(0.2 \% \mathrm{P} / \mathrm{kg}$ of $\mathrm{DM})$ for a period of $4 \mathrm{wk}$. The depletion phase was preceded by a 2 -wk acclimatization period and followed by a 2-wk repletion phase, during which the same ration was supplemented with $\mathrm{P}$ to meet or exceed daily requirements. Blood samples were collected at the end of the acclimatization period, after 2 and 4 wk of $\mathrm{P}$ depletion, and at the end of the repletion phase. Plasma phosphate concentrations $([\mathrm{Pi}])$ were determined and white blood cells were counted and isolated. General immune function was investigated by performing a phagocytosis assay with Staphylococcus aureus and a lymphocyte stimulation test (LST) with concanavalin A and pokeweed mitogen. The plasma [Pi] decreased significantly, with the lowest values (mean $0.7 \pm 0.2 \mathrm{mmol} / \mathrm{L}$ ) occurring after 2 wk of depletion, although depletion was continued for another 2 wk. During repletion, plasma $[\mathrm{Pi}]$ increased above baseline concentrations. Granulocyte counts changed in parallel with plasma $[\mathrm{Pi}]$ over time, decreasing significantly at 2 wk after $\mathrm{P}$ depletion and increasing again thereafter. Granulocyte survival after phagocytosis was lowest after 4 wk of $\mathrm{P}$ depletion. Phagocytosis activity of surviving granulocytes determined by mean fluorescence
\end{abstract}

Received March 28, 2014.

Accepted May 3, 2014.

${ }^{1}$ Corresponding author: s.w.f.eisenberg@uu.nl

${ }^{2}$ Current address: Clinic for Cattle, University of Veterinary Medicine Hannover, Foundation, Bischofsholer Damm15, D-30173 Hanover, Germany. intensity was higher, indicating that phagocytosis was not negatively influenced by $\mathrm{P}$ depletion. Lymphocyte stimulation showed a similar trend, with a decreasing stimulation index at the end of $\mathrm{P}$ depletion, but differences were not statistically significant. Data presented in this study indicate that hypophosphatemia leads to a decrease in granulocyte counts. Chronic P depletion impairs granulocyte survival during phagocytosis but not phagocytosis activity. Lymphocyte function is not influenced by $\mathrm{P}$ depletion.

Key words: dairy cow, phosphorus depletion, hypophosphatemia, leucocyte function

\section{INTRODUCTION}

Phosphorus in dairy cows has received increased attention over the past decades because of environmental concerns with excessive fecal $\mathrm{P}$ excretion and also because of empirical associations that were made between $\mathrm{P}$ depletion and clinical signs such as muscle weakness and recumbency or postparturient hemoglobinuria, a condition associated with severe intravascular hemolysis (Gerloff and Swensen, 1996; Stockdale et al., 2005). Legal regulations limiting the $\mathrm{P}$ content in soil have led to incentives to reduce the dietary $\mathrm{P}$ content of ruminant feed to reduce the $\mathrm{P}$ content in manure. Current estimates for dietary $\mathrm{P}$ requirements for dairy cows have been shown to be adequate, although the adequacy of currently used $\mathrm{P}$ requirements has been studied mainly in the light of reproductive performance, milk production, and bone stability (Valk and Šebek, 1999; Wu and Satter, 2000; Wu et al., 2000; Valk et al., 2002). Notwithstanding, concerns have been raised for periparturient dairy cows, where $\mathrm{P}$ requirements for milk production increase with continuously increasing milk yields, whereas the dietary $\mathrm{P}$ content is restricted and feed intake is at its nadir around parturition. Hypophosphatemia, which is widely used as indicator for $\mathrm{P}$ depletion, was observed in over $10 \%$ of dairy cows in early lactation in one study (Macrae et al., 2006). Although the clinical relevance of subnormal serum phosphate concentrations ([Pi] ) is currently poorly understood, hypophosphatemia has been incriminated 
as a potential cause for the downer cow syndrome and postparturient hemoglobinuria (Gerloff and Swensen, 1996; Stockdale et al., 2005).

In other species, $\mathrm{P}$ status has been shown to influence cellular immune function (Craddock et al., 1974; Fuller et al., 1976; Brautbar et al., 1982; Kiersztejn et al., 1992; Kegley et al., 2001). In piglets, a high-P diet led to an increase of blastogenic responses of lymphocytes, whereas a low-P diet in rats, dogs, and humans impaired phagocytosis of PMNL (Craddock et al., 1974; Kegley et al., 2001). A reduction in ATP concentration and an increase in intracellular Ca concentration have been proposed to be the cause of this phenomenon (Kiersztejn et al., 1992).

Impaired immune function around parturition has been described in dairy cattle (Kehrli and Goff, 1989), presumably caused by hormonal and metabolic changes, including Ca depletion (Dosogne et al., 1999; Hammon et al., 2006; Martinez et al., 2014). No influence of P on immune function in lactating dairy cows was detected when feeding diets according to NRC (2001) guidelines or above the $\mathrm{P}$ requirements (Mullarky et al., 2009). However, feeding cows below currently recommended $\mathrm{P}$ requirements has, to our knowledge, not yet been studied. Therefore, the objective of the study presented here was to explore the effect of marked dietary $\mathrm{P}$ depletion over a course of $4 \mathrm{wk}$ in lactating dairy cows by a general assessment of PMNL and lymphocyte function determined by a phagocytosis and lymphoproliferation assay, respectively. We hypothesized that chronic $\mathrm{P}$ depletion interferes with the cellular immune function in dairy cows.

\section{MATERIALS AND METHODS}

\section{Experimental Design}

All procedures and treatments were approved by the Ethical Committee for Animal Experiments of Utrecht
University (Utrecht, the Netherlands) and performed according to their regulations.

Eight Holstein Friesian dairy cows (parity $\geq 3$ ) in mid lactation were enrolled in this experiment. Cows were housed in tie-stalls on rubber mats covered with sawdust in a temperature-controlled building. Cows were clinically healthy based on physical, blood biochemical, and hematological examination. The study consisted of a 2-wk acclimatization, a 4-wk $\mathrm{P}$ depletion, and a 2-wk P repletion period (Figure 1). Cows were fed the same base TMR, based on corn silage, grass seed straw, and beet pulp for the entire study period. This base TMR was formulated to meet the dietary requirements for lactating dairy cows, with the exception of the dietary P content (NRC, 2001). The unsupplemented ration containing $0.2 \% \mathrm{P} / \mathrm{kg}$ of $\mathrm{DM}$, was fed during the entire $\mathrm{P}$-depletion phase, but was supplemented with $\mathrm{NaH}_{2} \mathrm{PO}_{4}$ to obtain a dietary $\mathrm{P}$ content of $0.36 \% \mathrm{P} / \mathrm{kg}$ of DM during the acclimatization period and $0.45 \% \mathrm{P} /$ $\mathrm{kg}$ of DM during the repletion period. Cows were fed ad libitum at 0700 and $1900 \mathrm{~h}$ and had free access to water at all times. Cows were milked twice per day before feeding. The health status of the cows was monitored on a daily basis.

\section{Blood Sampling}

Blood samples were collected at the end of the acclimatization period, 2 and 4 wk after the onset of $\mathrm{P}$ depletion as well as at the end of the repletion period (Figure 1). Blood was collected by venipuncture of a jugular vein using a 20-G Vacuette needle (Greiner Bio-One GmbH, Kremsmünster, Austria) and EDTA, Li-heparin, and serum tubes (Greiner Bio-One $\mathrm{GmbH}$ ). Blood with EDTA was collected for leucocyte isolation and for determination of the leucocyte count and heparinized blood was required for the determination of the plasma [Pi]. Serum samples were only collected at the first sampling time. Serum samples were pooled

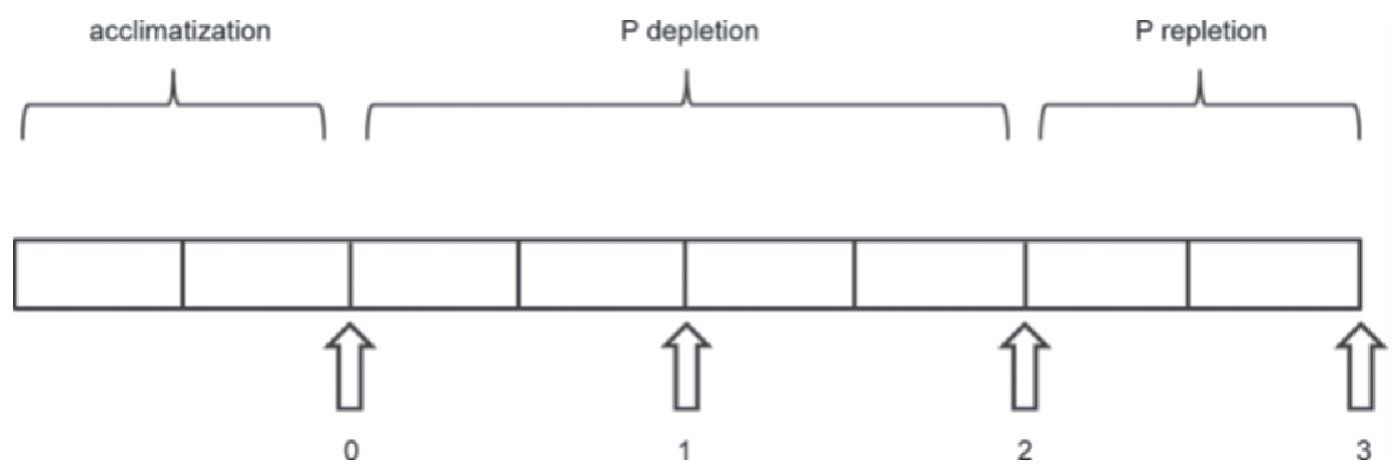

Figure 1. Timeline of the study. Each box represents $1 \mathrm{wk}$. Arrows indicate the time points of blood collection. 
and used for bacterial opsonization before phagocytosis experiments throughout the study.

\section{Hematology and Blood Biochemistry}

Leucocyte counts and leukocyte cell differentiation were conducted on an automated hematology system on EDTA blood within $1 \mathrm{~h}$ of sample collection (ADVIA 120 hematology system; Bayer AG, Leverkusen, Germany).

Heparin tubes were centrifuged at $1,600 \times g$ for 15 min at room temperature. Harvested plasma was stored at $-18^{\circ} \mathrm{C}$ until analyzed for plasma [Pi] spectrophotometrically (ammonium molybdate; DXC-600; Beckman Coulter Inc., Brea, CA).

\section{Leucocyte Isolation and Phenotyping}

Leucocytes were isolated under sterile conditions using hypertonic lysis. Nine milliliters of distilled water was added to $3 \mathrm{~mL}$ of EDTA blood and, after $30 \mathrm{~s}, 1$ $\mathrm{mL}$ of $10 \times$ PBS (Lonza Group AG, Basel, Switzerland) was added to reestablish iso-osmolarity. Tubes were centrifuged at $350 \times g$ for $4 \mathrm{~min}$ at room temperature to accumulate cells in the pellet. After washing the cells twice in PBS, the cell pellet was resuspended in $1 \mathrm{~mL}$ of PBS and counted using a Bürker-Türk cell counting chamber (VWR International BV, Amsterdam, the Netherlands). Viability of leucocytes was assayed using the trypan blue exclusion method and exceeded $98 \%$ in all samples. Leucocyte suspensions of a concentration of $1 \times 10^{7}$ cells $/ \mathrm{mL}$ were prepared and used for phenotyping, the phagocytosis assay, and the lymphocyte stimulation assay.

For phenotyping, $100 \mu \mathrm{L}$ of the cell suspension was added into wells of a 96-well round-bottom plate. Cells were washed once again with PBS in the microtiter plate. After centrifuging the plate at $350 \times g$ for $4 \mathrm{~min}$ at room temperature, the supernatant was removed and $50 \mu \mathrm{L}$ of the subset-specific first antibody (see below) was added into each well and incubated for 30 min at $4^{\circ} \mathrm{C}$. After incubation, the centrifugation and wash step with PBS was repeated before incubating the cells again with the second antibody for 30 min at $4^{\circ} \mathrm{C}$. After the second incubation, the excess antibody was removed by washing the cells twice. Labeled cells were fixated with phosphate-buffered $2 \%$ formaldehyde for about $15 \mathrm{~min}$ at $4^{\circ} \mathrm{C}$. Formaldehyde was removed by 2 PBS washing steps before cells were resuspended in FACS buffer $[1 \times$ PBS, 10\% FCS (Lonza Group AG), and $0.1 \%$ sodium azide (Sigma-Aldrich Chemie BV, Zwijndrecht, the Netherlands)] and measured by flow cytometer (BD FACSCanto II flow cytometer; Becton Dickinson Immunocytometry Systems, San Jose, CA).
With specific antibodies targeting different cell markers, white blood cell (WBC) populations were identified as $\mathrm{T}$ cells and natural killer (NK) cells [cluster of differentiation (CD) 2; ILA-42 biotinylated with streptavidin: Alexa Fluor 633; AbD Serotec, Kidlington, UK], cytotoxic T cells (CD8; CC63 mouse $\alpha$-bovine RPE; AbD Serotec), monocytes and macrophages (CD14; TÜK4 mouse $\alpha$-human AlexaFluor 647; AbD Serotec), B cells (CD21; CC21 mouse $\alpha$-bovine FITC; AbD Serotec), and T helper cells [CD4; CC8 mouse $\alpha$-bovine R-phycoerythrin (RPE); AbD Serotec] to study changes in WBC populations over time. Cell populations were identified by forward-sideward scatter (FSC-SSC) and further separated by fluorescence signal using FlowJo flow cytometry analysis software (FlowJo X; TreeStar Inc., Ashland, OR). Relative numbers of cell populations identified by flow cytometric analysis were multiplied by leucocyte counts to get absolute numbers of cells.

\section{Fluorescent Labeling of Staphylococcus aureus}

Staphylococcus aureus (SA; strain S1444), grown on sheep-blood agar, was grown overnight in lysogeny broth at $37^{\circ} \mathrm{C}$ on a shaker at $100 \mathrm{rpm}$. Concentration of the culture was determined by optical density at 600 $\mathrm{nm}$ using a spectrophotometer. Bacterial labeling was performed using a DyLight 488 Antibody Labeling Kit (Thermo Scientific, Pierce Biotechnology Inc., Rockford, IL) according to the manufacturer's instructions. After incubation, bacteria were washed 4 times with PBS to completely remove unbound label. Bacteria were resuspended to achieve the starting concentration and aliquoted in 1.5-mL microtiter tubes. A serial 10fold dilution was prepared and $50 \mu \mathrm{L}$ was cultured on sheep blood agar to determine the final concentration of viable bacteria of the prepared SA suspension. The SA aliquots were stored at $-20^{\circ} \mathrm{C}$ until the phagocytosis assay.

\section{Phagocytosis Assay}

An SA suspension of $2 \times 10^{7}$ bacteria $/ \mathrm{mL}$ was prepared in culture medium with $10 \%$ pooled bovine serum and $100 \mu \mathrm{L}$ of the suspension was pipetted per well of a 96-well round-bottom plate. The plate was kept at $37^{\circ} \mathrm{C}$ for $10 \mathrm{~min}$. The cell suspension $(10 \mu \mathrm{L})$ was pipetted into each well to achieve a final ratio of cell to SA of 1:20 and samples were incubated for 30 min at 4 and $37^{\circ} \mathrm{C}$. Incubation conditions with $\mathrm{SA}$ at $4^{\circ} \mathrm{C}$ and with culture medium without $\mathrm{SA}$ at $37^{\circ} \mathrm{C}$ were used as a negative control. Phagocytosis was stopped by placing the microtiter plate on ice and adding icecold phosphate-buffered formaldehyde (final concentra- 
tion of $2 \%$ ). Samples were incubated at $4^{\circ} \mathrm{C}$ for $15 \mathrm{~min}$. Phosphate-buffered formaldehyde was removed by 2 PBS washing steps, after which cells were resuspended in $100 \mu \mathrm{L}$ of FACS buffer and measured by flow cytometer.

For the determination of phagocytosis, granulocytes were selectively gated on FSC-SSC using FlowJo software. Phagocytosis, as opposed to adherence, was confirmed by confocal microscopy (Leica SPE-II; Leica Microsystems, Wetzlar, Germany) and the degree of phagocytosis was determined by separating granulocytes by the fluorescence signal produced by ingested labeled SA bacteria. The percentage fluorescent granulocytes was used as a proxy for the number of phagocytizing granulocytes. In addition, the mean fluorescent intensity (MFI) of granulocytes was determined as a measure of the number of bacteria phagocytized per cell.

\section{Lymphocyte Stimulation}

Cell and mitogen preparations for lymphoproliferative response were prepared under sterile conditions. Cells were stimulated with concanavalin $\mathrm{A}$ in a final concentration of $5 \mu \mathrm{g} / \mathrm{mL}$ and pokeweed mitogen in a final concentration of $5 \mu \mathrm{g} / \mathrm{mL}$ for $66 \mathrm{~h}$ at $37^{\circ} \mathrm{C}$. Mitogens were diluted in culture medium to achieve the desired concentration. Medium without mitogen was used as a negative control. Cell suspension $(100 \mu \mathrm{L})$ and 100 $\mu \mathrm{L}$ of medium, concanavalin $\mathrm{A}$, and pokeweed mitogen were added into each well of a 96-well flat-bottom plate and incubated. After $66 \mathrm{~h}$, cell proliferation was confirmed under the light microscope before the cell suspensions were mixed by pipetting and measured by flow cytometer for blastogenesis of lymphocytes. Based on the FSC-SSC parameters, a gate was set where the stimulated as well as the unstimulated peripheral blood mononuclear cell populations were expected based on pilot experiments. Data for $1 \times 10^{4}$ gated cells were collected. For analysis in FlowJo software, 2 gates were set in the unstimulated sample, one around the unstimulated mononuclear leukocytes (A) and a second one for the expected stimulated cells (B). Gates were then transferred to stimulated samples. Stimulation for each treatment was computed by the formula $\mathrm{B} /(\mathrm{A}+\mathrm{B})$. For final analysis the stimulation index was determined by the mitogen-to-medium ratio.

\section{Data Analysis}

Flow cytometer data, as produced by FlowJo software, were prepared for statistical analysis in Microsoft Excel software (Microsoft Office 2010; Microsoft Corp., Redmond, WA). Statistical analysis was performed us- ing the SPSS statistical software package (IBM SPSS statistics 20.0; IBM Corp., Armonk, NY). Data are presented as medians with quartiles and $95 \%$ confidence intervals. For graphical presentation of data, GraphPad Prism software (6.01; GraphPad Software Inc., La Jolla, CA) was used. Data were checked for normality and whenever necessary logarithmically transformed to achieve a normal distribution. Plasma [Pi], cell counts, percentage of granulocytes, percentage of phagocytizing granulocytes, MFI, and the lymphocyte stimulation index were analyzed for time effects between the different sampling points using a repeated-measures ANOVA. Differences were considered to be significant at $P<0.05$.

\section{RESULTS}

\section{Plasma [Pi] and WBC Populations}

All cows remained clinically healthy and completed the entire study. Plasma $[\mathrm{Pi}]$ over time are presented in Figure 2. Plasma $[\mathrm{Pi}]$ were within normal limits [mean: $1.3 \pm 0.36 \mathrm{mmol} / \mathrm{L}$; reference range: $1.3-2.6 \mathrm{mmol} / \mathrm{L}$ (Goff, 2004)] at the end of the acclimatization period. The mean plasma $[\mathrm{Pi}]$ reached its nadir after 2 wk of $\mathrm{P}$ depletion, with a mean of $0.7 \pm 0.2 \mathrm{mmol} / \mathrm{L}$, which was approximately $50 \%$ below baseline values. A numerical increase in the plasma $[\mathrm{Pi}]$ was noted in the following 2 wk of $\mathrm{P}$ depletion despite unchanged dietary $\mathrm{P}$ content. A rapid increase in plasma [Pi] above baseline concentrations was observed in all cows at the end of the repletion period (Figure 2).

Results of the WBC phenotyping are shown in Table 1. Within the first 2 wk of $\mathrm{P}$ depletion, the granulocyte count decreased significantly (Figure 3a), reaching its nadir at this time point. Although $\mathrm{P}$ depletion continued for another $2 \mathrm{wk}$, granulocyte count increased again, paralleling the development of the plasma [Pi] over time. However, during repletion, the granulocyte count did not return to the baseline level. The B-cell counts showed a similar pattern (Figure 3b). Total Tcell counts showed an inversed pattern compared with granulocytes and B cells (Figure 3c); however, changes were not significant over time.

\section{Phagocytosis}

The percentage of total granulocytes after incubation with SA at $37^{\circ} \mathrm{C}$ was significantly below the percentage of granulocytes after incubation with $\mathrm{SA}$ at $4^{\circ} \mathrm{C}$ at all sampling times $(P<0.001$; Figures $4 \mathrm{a}$ and $\mathrm{b})$. The percentage granulocytes after incubation with $\mathrm{SA}$ at $4^{\circ} \mathrm{C}$ and the percentage granulocytes incubated with culture medium at $37^{\circ} \mathrm{C}$ were comparable at all sampling times 
Table 1. Mean cell counts (with SD in parentheses; $n=8$ ) of the individual lymphocyte populations as determined by multiplying the relative number of cells achieved by flow cytometric analysis with the leucocyte count

\begin{tabular}{|c|c|c|c|c|c|}
\hline \multirow{2}{*}{$\begin{array}{l}\text { Cell } \\
\text { marker }^{1}\end{array}$} & \multirow[b]{2}{*}{ Cell type } & \multicolumn{4}{|c|}{ Sampling, $\times 10^{9} / \mathrm{L}$} \\
\hline & & 0 & 1 & 2 & 3 \\
\hline CD2 & $\mathrm{T}$ cells and natural killer (NK) cells & $0.21(0.07)$ & $0.36(0.12)$ & $0.29(0.08)$ & $0.24(0.09)$ \\
\hline CD4 & $\mathrm{T}$ helper cells & $0.03(0.02)$ & $0.08(0.04)$ & $0.04(0.02)$ & $0.05(0.03)$ \\
\hline $\mathrm{CD} 8$ & Cytotoxic T cells & $0.01(0.01)$ & $0.04(0.03)$ & $0.02(0.01)$ & $0.03(0.02)$ \\
\hline CD14 & Monocytes and macrophages & $0.07(0.03)$ & $0.13(0.04)$ & $0.09(0.03)$ & $0.10(0.05)$ \\
\hline CD21 & B cells & $0.73(0.07)$ & $0.54(0.08)$ & $0.62(0.13)$ & $0.60(0.12)$ \\
\hline
\end{tabular}

${ }^{1} \mathrm{CD}=$ cluster of differentiation.

(results not shown). The percentage of total granulocytes and the percentage phagocytizing granulocytes were significantly lower after 4 wk of $\mathrm{P}$ depletion than at the end of the repletion period (Figures $4 \mathrm{~b}$ and $\mathrm{c}$ ). Changes in the percentage of granulocytes after incubation in the medium control samples (results not shown) were similar to changes observed in samples incubated with SA at $37^{\circ} \mathrm{C}$. The MFI values were significantly higher at after 4 wk of $\mathrm{P}$ depletion than at the end of the repletion period (Figure 4d.).

\section{Lymphocyte Stimulation}

Lymphocyte stimulation throughout the study is shown in Figure 5. Although a trend toward a decrease

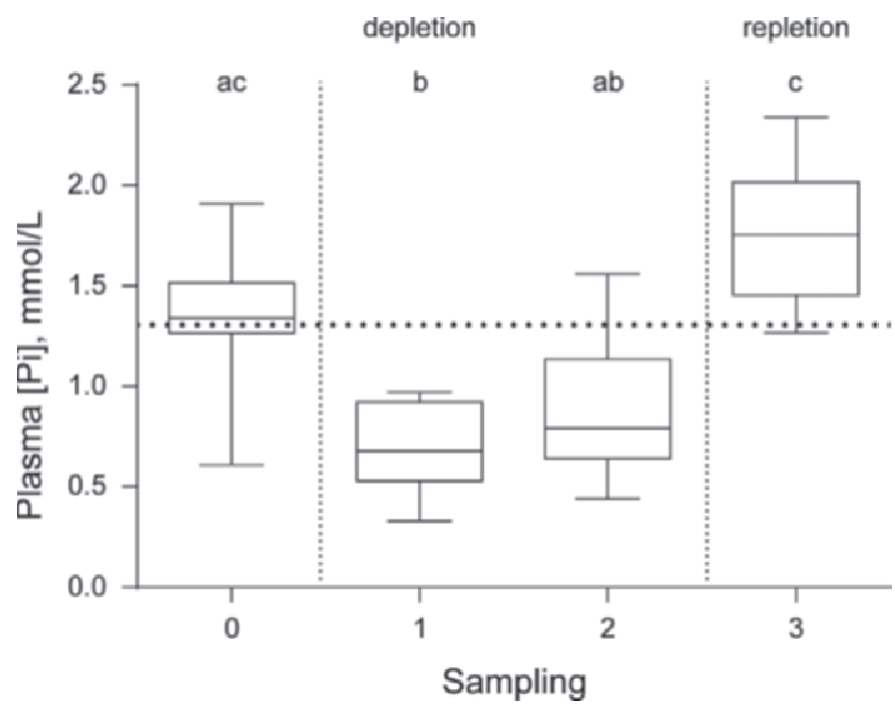

Figure 2. Plasma phosphate concentration $([\mathrm{Pi}])$ at different sampling times. Samplings 0, 1, 2, and 3 represent the end of the acclimatization period, 2 and 4 wk of $\mathrm{P}$ depletion, and the end of the repletion period, respectively. Vertical dotted lines indicate the beginning and end of the P-depletion period. The dotted horizontal line represents the lower end of the plasma $[\mathrm{Pi}]$ reference range $(1.3-2.6 \mathrm{mmol} / \mathrm{L})$. Sampling times with different letters $(\mathrm{a}-\mathrm{c})$ differ significantly from each other $(P<0.05)$. Medians and quartiles are displayed in the box. Whiskers represent the $95 \%$ CI in proliferation during $\mathrm{P}$ depletion was seen, no statistical significant changes in lymphoproliferation were identified.

\section{DISCUSSION}

The objective of the present study was to determine the effect of dietary $\mathrm{P}$ depletion on leukocyte function in lactating dairy cows. To our knowledge, this is the first study to explore the effect of transient dietary $\mathrm{P}$ depletion and repletion on cellular immune function in lactating dairy cows. So far, only the influence of a low-P diet $[0.34 \% \mathrm{P} / \mathrm{kg}$ of $\mathrm{DM}$; recommended $\mathrm{P}$ level is 0.32 to $0.44 \%$ (NRC, 2001)] on immune function of dairy cows was studied, indicating no negative effect (Mullarky et al., 2009).

Due to a decrease in feed intake around parturition and the sudden onset of milk production, hypophosphatemia is a common finding in periparturient dairy cows (Staufenbiel et al., 2002; Macrae et al., 2006; Grünberg, 2008, 2014). Periparturient conditions, such as downer cow syndrome and postparturient hemoglobinuria, are widely believed to be associated with hypophosphatemia (Gerloff and Swensen, 1996; Stockdale et al., 2005). Impairment of immune function has been described in states of $\mathrm{P}$ depletion in other species (Craddock et al., 1974; Alexiewicz et al., 1991; Kegley et al., 2001). However, the complexity of metabolic and endocrine changes affecting the immune response of the periparturient cow make it difficult to assess the immunomodulatory effect of $\mathrm{P}$ deficiency on its own (Kehrli and Goff, 1989; Hammon et al., 2006; Martinez et al., 2014). To circumvent confounding effects commonly present in periparturient cows, we studied the effect of $\mathrm{P}$ depletion and hypophosphatemia on immune function in healthy mid-lactation cows. As an indicator of cellular immune function, a general assessment of phagocytosis activity of granulocytes and the ability of T-cell activation as a central point in adaptive immune responses through monitoring their frequencies and general activation capabilities was chosen, as is widely 

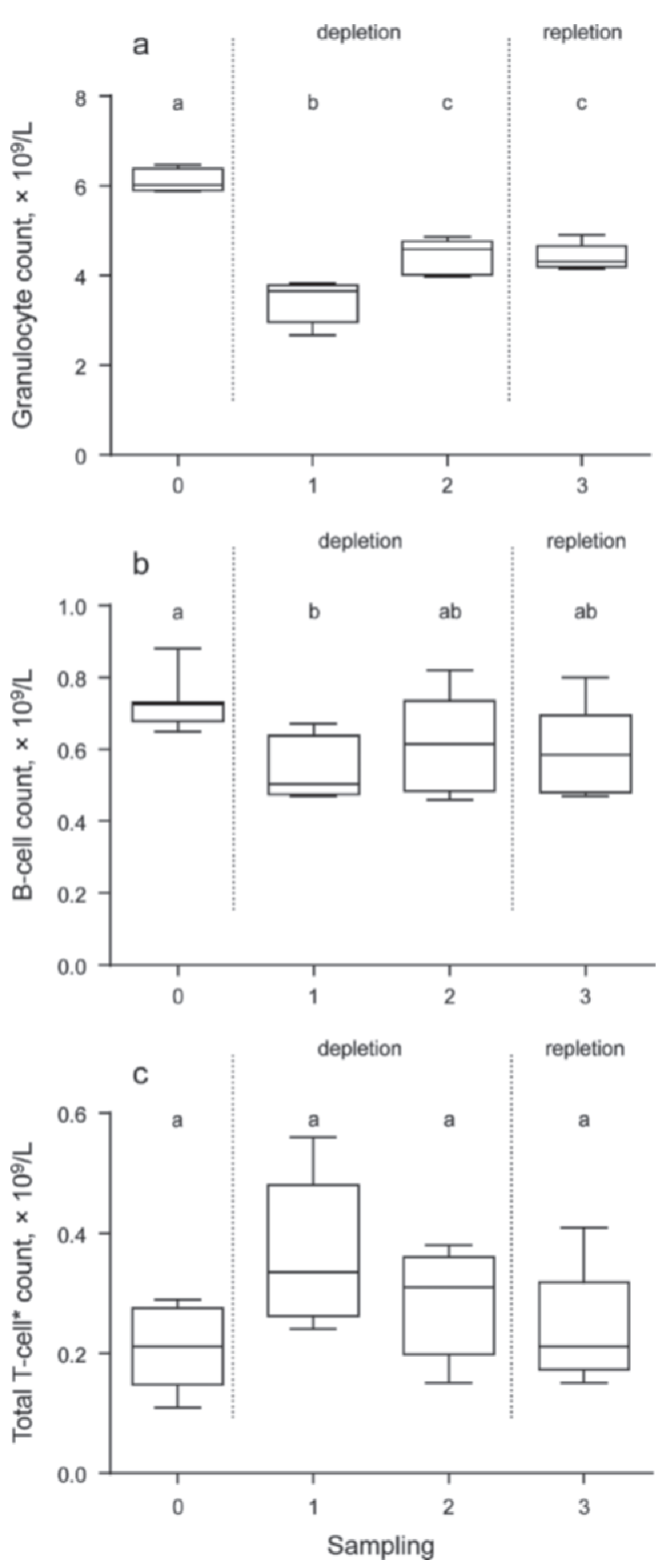

Figure 3. Granulocyte (panel a), B-cell (panel b), and total T-cell counts (panel c) at different sampling times. Samplings $0,1,2$, and 3 represent the end of the acclimatization period, 2 and 4 wk of $\mathrm{P}$ depletion, and the end of the repletion period, respectively. Vertical dotted lines indicate the starting and end of the P-depletion period. Sampling periods with different letters $(\mathrm{a}-\mathrm{c})$ differ significantly from each other $(P<0.05)$. Medians and quartiles are displayed in the box. Whiskers represent the $95 \%$ CI. ${ }^{*}$ Total T-cell counts $=$ cluster of differentiation 2 (CD2)-positive cells. accepted (Roth and Kaeberle, 1981; Saad et al., 1989; Kegley et al., 2001).

Feeding a diet deficient in $\mathrm{P}$ decreases plasma $[\mathrm{Pi}]$ (Wu and Satter, 2000; Knowlton and Herbein, 2002; Grünberg, 2014). Development of the plasma [Pi] over time in the present study indicates that the dietary $\mathrm{P}$ content in the experimental ration was adequate to achieve $\mathrm{P}$ depletion in the cows in the study. After 2 wk of $\mathrm{P}$ depletion, the mean plasma $[\mathrm{P}]$ of the cows in the study had declined by almost $50 \%$ to a mean plasma $[\mathrm{Pi}]$ of $0.7 \pm 0.2 \mathrm{mmol} / \mathrm{L}$. The mean plasma [Pi] increased numerically but not significantly again during the second part of the depletion phase despite unchanged dietary $\mathrm{P}$ content, which is likely the result of counterregulatory mechanisms, which include mobilization of P from bone (Annenkov, 1982; Valk et al., 2002).

The changes observed in granulocyte and B-cell counts were similar to the pattern of the plasma [Pi], with the nadir after 2 wk of $\mathrm{P}$ depletion. This finding suggests that $\mathrm{P}$ depletion may affect bone marrow activity, leading to a reversible bone marrow depression, resulting in a significant decrease in the number of circulating granulocytes and B-cells.

Phagocytic activity of granulocytes in relation to plasma $[\mathrm{Pi}]$ was assessed by measuring phagocytosis after incubation with SA. Incubation of granulocytes with $\mathrm{SA}$ at $37^{\circ} \mathrm{C}$ led to a significant decrease in percentage of granulocytes compared with granulocytes incubated with culture medium without $\mathrm{SA}$ at $37^{\circ} \mathrm{C}$ (results not shown) or SA at $4^{\circ} \mathrm{C}$ (Figures $4 \mathrm{a}$ and b), indicating that only active granulocyte-SA interaction enhanced cell death. This decrease might have been caused either by enhanced programmed cell death (apoptosis) of the granulocyte or, as viable bacteria were used in this study, by the production of leukocidins by SA (Harshman et al., 1989). Upregulation of key effector genes encoding apoptosis and downregulation of antiapoptosis genes has been described in human neutrophils after phagocytosis of different pathogens, including SA (Kobayashi et al., 2003). Apoptosis of bovine mammary epithelial cells after internalization of SA has been described (Bayles et al., 1998). The changes in percentage of phagocytizing granulocytes over time showed a pattern similar to the change in percentage of granulocytes after incubation with SA at $37^{\circ} \mathrm{C}$ (Figures $4 \mathrm{~b}$ and $\mathrm{c}$ ). Both decreased during dietary $\mathrm{P}$ depletion; however, the lowest measurement was detected 2 wk after the lowest plasma [Pi], but increased again when dietary $\mathrm{P}$ was supplemented. These findings suggest that either hypophosphatemia had a delayed effect on granulocyte survival or that the decline of the number of granulocytes detected 2 wk prior was compensated by enhanced granulopoiesis, leading to 

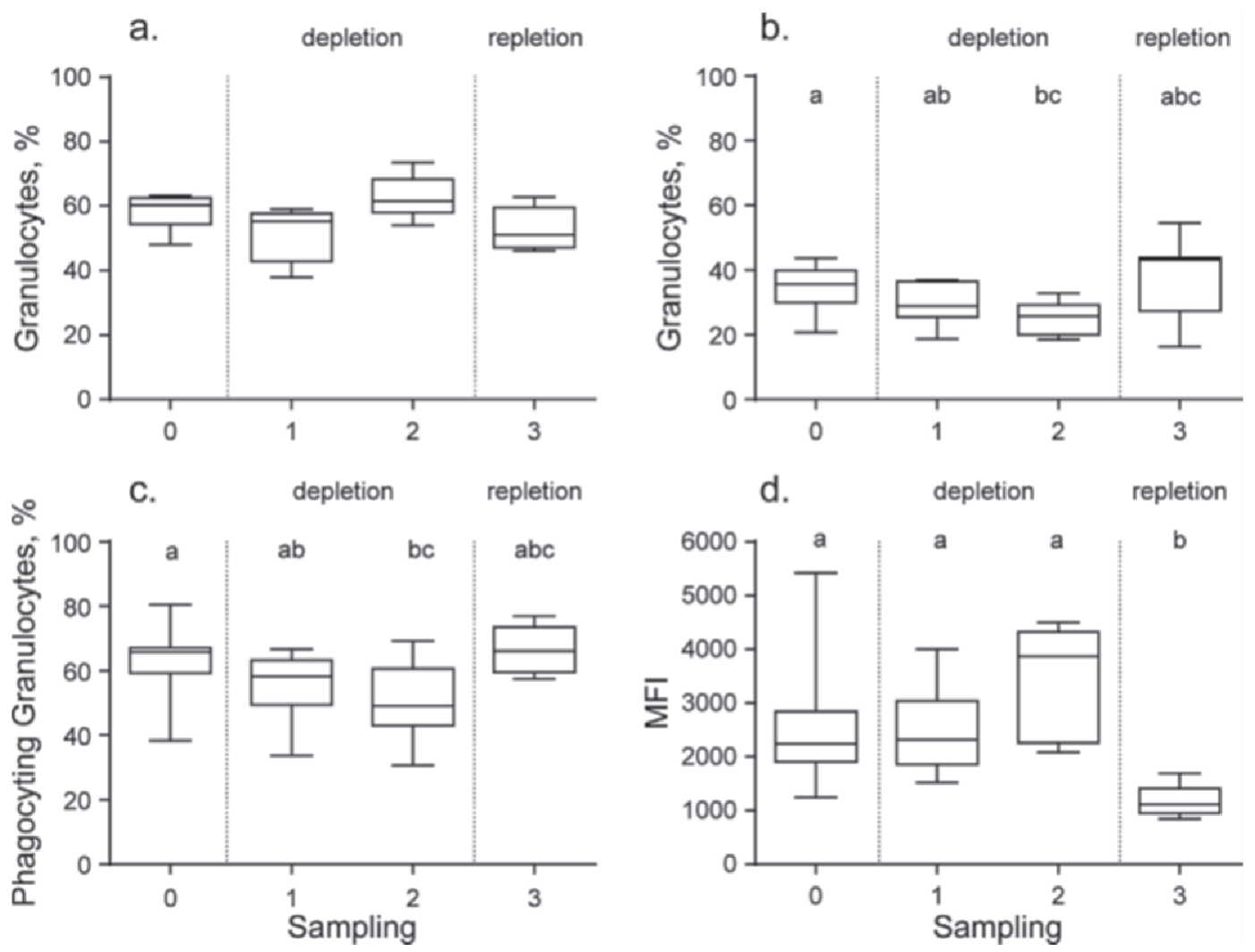

Figure 4. The percentage of total granulocytes after $30 \mathrm{~min}$ of Staphylococcus aureus (SA) incubation at $4^{\circ} \mathrm{C}$ (panel a), SA incubation at $37^{\circ} \mathrm{C}$ (panel b), the percentage of SA phagocytizing granulocytes at $37^{\circ} \mathrm{C}$ (panel c), and the mean fluorescence intensity (MFI) of granulocytes after SA incubation at $37^{\circ} \mathrm{C}$ (panel d) during the study period. The percentage of granulocytes after incubation with $\mathrm{SA}$ at $4^{\circ} \mathrm{C}($ panel a) and $\mathrm{SA}$ at $37^{\circ} \mathrm{C}$ (panel b) differed significantly from each other at all sampling points. Samplings 0, 1, 2, and 3 represent the end of the acclimatization period, 2 and 4 wk of $\mathrm{P}$ depletion, and the end of the repletion period, respectively. Vertical dotted lines indicate the beginning and end of the P-depletion period. Sampling periods with different letters $(\mathrm{a}-\mathrm{c})$ differ significantly from each other $(P<0.05)$. Medians and quartiles are displayed in the boxes. Whiskers represent the 95\% CI.

an increased number of younger, less functional granulocytes. Notwithstanding, the increase in MFI at the end of the dietary $\mathrm{P}$ depletion suggests that phagocytic function of viable cells was not affected by dietary $\mathrm{P}$ depletion. After in vitro incubation, a smaller number of granulocytes was found to be intact, which probably led to an increase in the cell:SA ratio and, therefore, to a higher number of phagocytized SA per cell, which resulted in a higher MFI. These results do not support an impairment of phagocytosis of granulocytes due to hypophosphatemia in dairy cows as described in other species (Craddock et al., 1974; Kegley et al., 2001).

In rats and humans, $\mathrm{P}$ depletion decreases the cytosolic ATP concentration and induces cellular Ca toxicity due to a significant increase in plasma and intracellular Ca concentrations ([Ca]; Kiersztejn et al., 1992; Massry and Fadda, 1993). High intracellular [Ca] interfere with mitochondrial oxidation and ATP synthesis and impair Ca signaling in the cell (Alexiewicz et al., 1991; Massry and Fadda, 1993) and, therefore, lead to a reversible loss of cell function in different cell types
(Massry et al., 1991; Zhou et al., 1991; Kiersztejn et al., 1992; Massry and Fadda, 1993). In addition, human and mouse erythrocytes have been shown to undergo rapid self-destruction and disintegration due to $\mathrm{Ca}$ influx (Bratosin et al., 2001; Birka et al., 2004). Similarly intra- and extracellular [Ca] have been described to be important for cell function of smooth muscle cells and PMNL in dairy cows (Jørgensen et al., 1998; Martinez et al., 2014). Elevated cytosolic [Ca] might have occurred due to an impairment of $\mathrm{Ca}^{2+}$ ATPase (Brautbar et al., 1983; Kiersztejn et al., 1992), leading to enhanced cell death of granulocytes.

Lymphocyte proliferation due to stimulation with concanavalin A and pokeweed mitogen did not show any significant changes during $\mathrm{P}$ depletion, although a similar trend compared with the phagocytosis was visible. In contrast, in piglets, a linear increase between the blastogenic response to phytohemagglutinin and $\mathrm{P}$ supplementation was documented (Kegley et al., 2001). It was hypothesized that the induction of blastogenesis by $\mathrm{P}$ was caused by a decrease in 1,25-dihydroxyvi- 


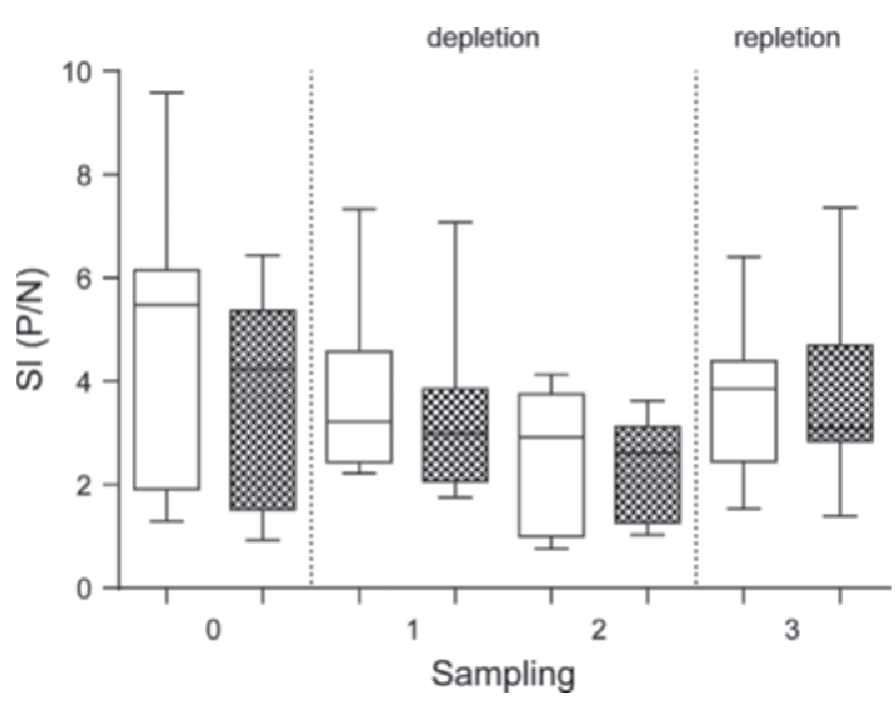

Figure 5. Results of the lymphoproliferation assay stimulated with concanavalin A (blank boxes) and with pokeweed mitogen (checked boxes). Samplings 0, 1, 2, and 3 represent the end of the acclimatization period, 2 and 4 wk of $\mathrm{P}$ depletion, and the end of the repletion period, respectively. Vertical dotted lines indicate the beginning and end of the P-depletion period. No significant differences between sampling periods were identified. Medians and quartiles are displayed in the boxes. Whiskers represent the $95 \%$ CI. SI $=$ stimulation index (positive-to-negative ratio).

tamin $\mathrm{D}_{3}$ concentration, which has a negative effect on lymphocyte proliferation (Kegley et al., 2001). In dairy cattle, no effect of $\mathrm{P}$ on 1,25-dihydroxyvitamin $\mathrm{D}_{3}$ was identified (Breves and Schröder, 1991; Peterson et al., 2005). As discussed previously, $\mathrm{P}$ depletion in rats interfered with cell function, including impaired T-cell function (Massry and Fadda, 1993). Although phagocytosis data presented in the current paper indicate a negative effect of dietary $\mathrm{P}$ depletion on phagocytizing bovine granulocyte life span, a negative influence on lymphocyte function in dairy cattle could not be identified.

\section{CONCLUSIONS}

The results of the present study support our hypothesis that chronic dietary $\mathrm{P}$ depletion interferes with cellular immunity in dairy cows, as indicated by a decrease in the number of granulocytes when plasma [Pi] decreased. In addition, at the end of the P-depletion phase, the percentage of granulocytes after incubation with SA decreased significantly, suggesting that chronic $\mathrm{P}$ depletion may impair granulocyte survival. However, the phagocytic capacity of granulocytes and lymphoproliferation were not influenced by chronic $\mathrm{P}$ depletion and, therefore, it seems unlikely that the reduction in dietary $\mathrm{P}$ concentration jeopardizes cow health by impairing cellular immune function.

\section{ACKNOWLEDGMENTS}

The authors acknowledge the technical assistance auf Paul Dobbelaar in formulating the experimental ration.

\section{REFERENCES}

Alexiewicz, J. M., M. Smogorzewski, G. Z. Fadda, and S. G. Massry. 1991. Impaired phagocytosis in dialysis patients: Studies on mechanisms. Am. J. Nephrol. 11:102-111.

Annenkov, B. N. 1982. Methods of determination of the requirements of farm animals for minerals. Pages 285-320 in Mineral Nutrition of Animals (Studies in the Agricultural \& Food Sciences). V. I. Georgievskii, ed. Butterworths, London, UK.

Bayles, K. W., C. A. Wesson, L. E. Liou, L. K. Fox, G. A. Bohach, and W. R. Trumble. 1998. Intracellular Staphylococcus aureus escapes the endosome and induces apoptosis in epithelial cells. Infect. Immun. 66:336-342.

Birka, C., P. Lang, D. Kempe, L. Hoefling, V. Tanneur, C. Duranton, S. Nammi, G. Henke, S. Myssina, M. Krikov, S. M. Huber, T. Wieder, and F. Lang. 2004. Enhanced susceptibility to erythrocyte "apoptosis" following phosphate depletion. Pflügers Arch. 448:471-477.

Bratosin, D., J. Estaquier, F. Petit, D. Arnoult, B. Quatannens, J.P. Tissier, C. Slomianny, C. Sartiaux, C. Alonso, J.-J. Huart, J. Montreuil, and J. C. Ameisen. 2001. Programmed cell death in mature erythrocytes: A model for investigating death effector pathways operating in the absence of mitochondria. Cell Death Differ. 8:1143-1156.

Brautbar, N., R. Baczynski, C. Carpenter, S. Moser, P. Geiger, P. Finander, and S. G. Massry. 1982. Impaired energy metabolism in rat myocardium during phosphate depletion. Am. J. Physiol. 242:F699-F704.

Brautbar, N., C. Carpenter, R. Baczynski, R. Kohan, and S. G. Massry. 1983. Impaired energy metabolism in skeletal muscle during phosphate depletion. Kidney Int. 24:53-57.

Breves, G., and B. Schröder. 1991. Comparative aspects of gastrointestinal phosphorus metabolism. Nutr. Res. Rev. 4:125-140.

Craddock, P. R., Y. Yawata, L. VanSanten, S. Gilberstadt, S. Silvis, and H. S. Jacob. 1974. Acquired phagocyte dysfunction-A complication of the hypophosphatemia of parenteral hyperalimentation. N. Engl. J. Med. 290:1403-1407.

Dosogne, H., C. Burvenich, A. E. Freeman, M. E. Kehrli Jr., J. C. Detilleux, J. Sulon, J. F. Beckers, and D. Hoeben. 1999. Pregnancy-associated glycoprotein and decreased polymorphonuclear leukocyte function in early post-partum dairy cows. Vet. Immunol. Immunopathol. 67:47-54.

Fuller, T. J., N. W. Carter, C. Barcenas, and J. P. Knochel. 1976 Reversible changes of the muscle cell in experimental phosphorus deficiency. J. Clin. Invest. 57:1019-1024.

Gerloff, B. J., and E. P. Swensen. 1996. Acute recumbency and marginal phosphorus deficiency in dairy cattle. J. Am. Vet. Med. Assoc. 208:716-719.

Goff, J. P. 2004. Macromineral disorders of the transition cow. Vet. Clin. North Am. Food Anim. Pract. 20:471-494.

Grünberg, W. 2008. Phosphorus homeostasis in dairy cattle: Some answers, more questions. Pages 29-35 in Proc. 17th Annu. TriState Dairy Nutr. Conf. The Ohio State University, Dept. Animal Science, Columbus.

Grünberg, W. 2014. Treatment of phosphorus balance disorders. Vet. Clin. North Am. Food Anim. Pract. http://dx.doi.org/10.1016/j. cvfa.2014.03.002.

Hammon, D. S., I. M. Evjen, T. R. Dhiman, J. P. Goff, and J. L. Walters. 2006. Neutrophil function and energy status in Holstein cows with uterine health disorders. Vet. Immunol. Immunopathol. 113:21-29.

Harshman, S., P. Boquet, E. Duflot, J. E. Alouf, C. Montecucco, and E. Papini. 1989. Staphylococcal alpha-toxin: A study of membrane penetration and pore formation. J. Biol. Chem. 264:14978-14984. 
Jørgensen, R. J., N. R. Nyengaard, S. Hara, J. M. Enemark, and P. H. Andersen. 1998. Rumen motility during induced hyper- and hypocalcaemia. Acta Vet. Scand. 39:331-338.

Kegley, E. B., J. W. Spears, and S. K. Auman. 2001. Dietary phosphorus and an inflammatory challenge affect performance and immune function of weanling pigs. J. Anim. Sci. 79:413-419.

Kehrli, M. E., Jr., and J. P. Goff. 1989. Periparturient hypocalcemia in cows: Effects on peripheral blood neutrophil and lymphocyte function. J. Dairy Sci. 72:1188-1196.

Kiersztejn, M., I. Chervu, M. Smogorzewski, G. Z. Fadda, J. M. Alexiewicz, and S. G. Massry. 1992. On the mechanisms of impaired phagocytosis in phosphate depletion. J. Am. Soc. Nephrol. 2:1484-1489.

Knowlton, K. F., and J. H. Herbein. 2002. Phosphorus partitioning during early lactation in dairy cows fed diets varying in phosphorus content. J. Dairy Sci. 85:1227-1236.

Kobayashi, S. D., K. R. Braughton, A. R. Whitney, J. M. Voyich, T. G. Schwan, J. M. Musser, and F. R. DeLeo. 2003. Bacterial pathogens modulate an apoptosis differentiation program in human neutrophils. Proc. Natl. Acad. Sci. USA 100:10948-10953.

Macrae, A. I., D. A. Whitaker, E. Burrough, A. Dowell, and J. M. Kelly. 2006. Use of metabolic profiles for the assessment of dietary adequacy in UK dairy herds. Vet. Rec. 159:655-661.

Martinez, N., L. D. P. Sinedino, R. S. Bisinotto, E. S. Ribeiro, G C. Gomes, F. S. Lima, L. F. Greco, C. A. Risco, K. N. Galvão, D. Taylor-Rodriguez, J. P. Driver, W. W. Thatcher, and J. E. P. Santos. 2014. Effect of induced subclinical hypocalcemia on physiological responses and neutrophil function in dairy cows. J. Dairy Sci. 97:874-887.

Massry, S. G., and G. Z. Fadda. 1993. Chronic renal failure is a state of cellular calcium toxicity. Am. J. Kidney Dis. 21:81-86.

Massry, S. G., S. M. Hajjar, P. Koureta, G. Z. Fadda, and M. Smogorzewski. 1991. Phosphate depletion increases cytosolic calcium of brain synaptosomes. Am. J. Physiol. 260:F12-F18.

Mullarky, I. K., W. A. Wark, M. Dickenson, S. Martin, C. S. Petersson-Wolfe, and K. F. Knowlton. 2009. Short communication:
Analysis of immune function in lactating dairy cows fed diets varying in phosphorus content. J. Dairy Sci. 92:365-368.

NRC. 2001. Nutrient Requirements of Dairy Cattle. 7th rev. ed. Natl. Acad. Press, Washington, DC.

Peterson, A. B., M. W. Orth, J. P. Goff, and D. K. Beede. 2005. Periparturient responses of multiparous Holstein cows fed different dietary phosphorus concentrations prepartum. J. Dairy Sci. 88:3582-3594.

Roth, J. A., and M. L. Kaeberle. 1981. Evaluation of bovine polymorphonuclear leukocyte function. Vet. Immunol. Immunopathol. $2: 157-174$.

Saad, A. M., C. Concha, and G. Aström. 1989. Alterations in neutrophil phagocytosis and lymphocyte blastogenesis in dairy cows around parturition. Zentralbl. Veterinärmed. B 36:337-345.

Staufenbiel, R., M. Dallmeyer, S. Horner, and C.-C. Gelfert. 2002. Neue Aspekte zum klinischen Bild und zur Therapie der Gebärparese des Rindes. VetMedReport 26(Sonderausg. V6):12.

Stockdale, C. R., T. E. Moyes, and R. Dyson. 2005. Acute post-parturient haemoglobinuria in dairy cows and phosphorus status. Aust. Vet. J. 83:362-366.

Valk, H., and L. B. J. Šebek. 1999. Influence of long-term feeding of limited amounts of phosphorus on dry matter intake, milk production, and body weight of dairy cows. J. Dairy Sci. 82:2157-2163.

Valk, H., L. B. J. Šebek, and A. C. Beynen. 2002. Influence of phosphorus intake on excretion and blood plasma and saliva concentrations of phosphorus in dairy cows. J. Dairy Sci. 85:2642-2649.

Wu, Z., and L. D. Satter. 2000. Milk production and reproductive performance of dairy cows fed two concentrations of phosphorus for two years. J. Dairy Sci. 83:1052-1063.

Wu, Z., L. D. Satter, and R. Sojo. 2000. Milk production, reproductive performance, and fecal excretion of phosphorus by dairy cows fed three amounts of phosphorus. J. Dairy Sci. 83:1028-1041.

Zhou, X.-J., G. Z. Fadda, A. F. Perna, and S. G. Massry. 1991. Phosphate depletion impairs insulin secretion by pancreatic islets. Kidney Int. 39:120-128. 